\title{
Experimental investigation of homogeneous freezing of sulphuric acid particles in the aerosol chamber AIDA
}

\author{
O. Möhler ${ }^{1}$, O. Stetzer ${ }^{1}$, S. Schaefers ${ }^{1}$, C. Linke ${ }^{1}$, M. Schnaiter ${ }^{1}$, R. Tiede ${ }^{1}$, H. Saathoff ${ }^{1}$, M. Krämer ${ }^{2}$, A. Mangold ${ }^{2}$, \\ P. Budz ${ }^{3}$, P. Zink ${ }^{3}$, J. Schreiner ${ }^{3}$, K. Mauersberger ${ }^{3}$, W. Haag ${ }^{4}$, B. Kärcher ${ }^{4}$, and U. Schurath ${ }^{1}$ \\ ${ }^{1}$ Forschungszentrum Karlsruhe (FZK), Institute of Meteorology and Climate Research (IMK-AAF), Karlsruhe, Germany \\ ${ }^{2}$ Forschungszentrum Jülich (FZJ), Institut für Chemie und Dynamik der Geosphäre (ICG-1), Jülich, Germany \\ ${ }^{3}$ Max-Planck-Institut für Kernphysik (MPIK), Abteilung Atmosphärenphysik, Heidelberg, Germany \\ ${ }^{4}$ Deutsches Zentrum für Luft- und Raumfahrt (DLR), Institut für Physik der Atmosphäre (IPA), Oberpfaffenhofen, Germany
}

Received: 27 August 2002 - Published in Atmos. Chem. Phys. Discuss.: 7 October 2002

Revised: 16 December 2002 - Accepted: 14 January 2003 - Published: 20 February 2003

\begin{abstract}
The homogeneous freezing of supercooled $\mathrm{H}_{2} \mathrm{SO}_{4} / \mathrm{H}_{2} \mathrm{O}$ solution droplets was investigated in the aerosol chamber AIDA (Aerosol Interactions and Dynamics in the Atmosphere) of Forschungszentrum Karlsruhe. 24 freezing experiments were performed at temperatures between 189 and $235 \mathrm{~K}$ with aerosol particles in the diameter range 0.05 to $1 \mu \mathrm{m}$. Individual experiments started at homogeneous temperatures and ice saturation ratios between 0.9 and 0.95 . Cloud cooling rates up to $-2.8 \mathrm{~K} \mathrm{~min}^{-1}$ were simulated dynamically in the chamber by expansion cooling using a mechanical pump. Depending on the cooling rate and starting temperature, freezing threshold relative humidities were exceeded after expansion time periods between about 1 and $10 \mathrm{~min}$. The onset of ice formation was measured with three independent methods showing good agreement among each other. Ice saturation ratios measured at the onset of ice formation increased from about 1.4 at $231 \mathrm{~K}$ to about 1.75 at $189 \mathrm{~K}$. The experimental data set including thermodynamic parameters as well as physical and chemical aerosol analysis provides a good basis for microphysical model applications.
\end{abstract}

\section{Introduction}

Homogeneous freezing of supercooled liquid aerosols is thought to be one of the key steps in the formation of cirrus clouds in the upper troposphere (Heymsfield and Miloshevich, 1993; Jensen et al., 1998) and of polar stratospheric clouds (PSCs) in the lower stratosphere (Jensen et al., 1991; Peter, 1997; Tabazadeh et al., 1997b; Carslaw et al., 1998a). Homogeneous freezing nucleation in atmospheric micrometer-sized aerosol droplets occurs at temperatures be-

Correspondence to: O. Möhler

(Ottmar.Moehler@imk.fzk.de) tween 235 and $185 \mathrm{~K}$ only if critical ice supersaturations of 40 to $70 \%$ are exceeded. High ice supersaturations are induced locally by orographic waves (Carslaw et al., 1998b; Jensen et al., 1998; Field et al., 2001), but are also measured quite frequently in wide-spread regions with different updraft velocities in the upper troposphere (Jensen et al., 1999; Gierens et al., 2000; Jensen et al., 2001). Numerous previous studies showed the importance of homogeneous freezing of sulphuric acid aerosols for cirrus cloud formation (Tabazadeh et al., 1997a; Jensen et al., 1998) and investigated climatically relevant cirrus properties like optical thickness (Jensen et al., 1994) or ice crystal number concentration, size and shape (Lawson et al., 1998). Modellers made first attempts to relate occurrence and properties of cirrus clouds to thermodynamic and microphysical formation mechanisms (Jensen and Toon, 1994; Kärcher, 2002; Kärcher and Lohmann, 2002). More recently, a global climate model was improved to interactively simulate cirrus cloud formation by homogeneous freezing (Lohmann and Kärcher, 2002).

Homogeneous freezing of supercooled aqueous solutions also occurs in polar stratospheric clouds which play a wellrecognized role in the antarctic and arctic stratospheric ozone loss due to heterogeneous activation of halogen reservoir species (Peter, 1997; Solomon, 1997). In the arctic stratosphere, formation of solid PSC particles is thought to be mainly initiated by homogeneous ice nucleation in supercooled ternary solution (STS) droplets which can be formed by uptake of water and nitric acid vapours into sulphuric acid particles at high cooling rates in orographic waves (Carslaw et al., 1997). Ice crystals growing in STS particles are also thought to provide a substrate for the formation of nitric acid trihydrate (NAT) particles (Carslaw et al., 1998a). Recent in situ measurements provided direct evidence for the existence

(C) European Geosciences Union 2003 
of NAT particles in the polar stratosphere (Schreiner et al., 1999; Voigt et al., 2000).

Homogeneous ice nucleation in aqueous particles was investigated in numerous laboratory studies, see Martin (2000) and references therein. In more recent laboratory studies of sulphuric acid solutions, the freezing was initiated by fast cooling of relatively large solution droplets deposited on a hydrophobic surface (Koop et al., 1998) or suspended in air passing a temperature controlled flow tube at high flow speed (Bertram et al., 1996; Prenni et al., 2001). The strong supercooling below the solution/ice coexistence temperature required for ice nucleation was achieved at almost constant solute concentration during the cooling period. In contrast, Chen et al. (2000) investigated homogeneous freezing of supercooled sulphuric acid aerosol particles at well controlled ice supersaturated conditions in a continuous flow diffusion chamber. The freezing onset was directly related to the temperature and relative humidity with respect to ice. Thermodynamic equilibrium composition of the aerosol particles was maintained by fast water vapour diffusion between the gas and condensed phases.

Recently, Koop et al. (2000) found that the ice nucleation rate in solutions of different chemical composition and solute concentration was almost the same for solutions of the same water activity at a given temperature. This work provides an activity-based parameterisation for treating homogeneous freezing in atmospheric models. To apply this parameterisation, the water activity of individual aerosol particles has to be known. In thermodynamic equilibrium, the water activity is directly related to the ambient temperature and relative humidity. However, the particle composition and therefore the water activity may also depend on kinetic effects, especially at high cooling rates in atmospheric waves or convective systems. Furthermore, the number and size of ice crystals in a cirrus cloud were shown to critically depend on the cooling rate during cirrus formation (Kärcher and Lohmann, 2002). Because complete sets of thermodynamic and aerosol data can hardly be obtained at high time resolution and precision during field studies, it is difficult to use field results for constraining numerical calculations with respect to ice nucleation mechanisms.

In this work, we present results of experiments on homogeneous ice nucleation in submicrometer-sized supercooled sulphuric acid aerosol droplets conducted at the AIDA aerosol chamber facility of Forschungszentrum Karlsruhe. Aerosol size distributions, temperatures, pressures, relative humidities and cooling rates during 24 individual expansion cooling experiments are typical for the upper troposphere and lower stratosphere. Number densities exceeded typical atmospheric conditions which, however, does not affect the applicability of the present study to atmospheric conditions. The instrumentation of the AIDA chamber provides comprehensive data on thermodynamic quantities, detailed information about the physical and chemical aerosol properties, as well as a sensitive detection of onset time of freez- ing and growing ice crystals with three independent methods. This paper concentrates on describing the experimental methods and discussing results. A companion paper (Haag et al., 2003) shows results obtained by comparing the experimental data with microphysical simulations of the ice initiation and the initial ice particle growth phase using the APSC (Advanced Particle Simulation Code) developed at Deutsches Zentrum für Luft- und Raumfahrt (DLR).

\section{Ice nucleation experiments}

\subsection{AIDA aerosol and cloud chamber facility}

Ice nucleation experiments were performed at the AIDA aerosol chamber facility of Forschungszentrum Karlsruhe (Nink et al., 2000; Möhler et al., 2001). Figure 1 shows a schematic cross section together with major technical components and scientific instrumentation used for ice nucleation experiments. The cylindrical aerosol vessel positioned inside a large isolating containment is made of $2 \mathrm{~cm}$ thick aluminium walls and has a height of $7 \mathrm{~m}$, a diameter of $4 \mathrm{~m}$, and a volume of $84 \mathrm{~m}^{3}$. The aerosol vessel can be evacuated to a final pressure of about $0.01 \mathrm{hPa}$ by two large mechanical pumps that can be operated at different pumping speeds. The interior of the containment, and thus the aluminium vessel, can be cooled to any temperature between ambient temperature and $183 \mathrm{~K}$ by circulating air through heat exchangers located at the bottom of the containment. Either a compressed cooling liquid (R404A) or liquid nitrogen is evaporated in the heat exchangers to achieve and maintain constant and homogeneous temperatures $\geq 233 \mathrm{~K}$ or $\geq 183 \mathrm{~K}$, respectively.

As will be described in Sects. 2.3 and 2.5, ice supersaturated conditions are established in the aerosol vessel by expansion cooling with a mechanical pump. The impact of the aluminium walls on the gas temperature and on the water vapour concentration during expansions will also be discussed in these sections.

The air temperature inside the isolating containment is measured with five thermocouples located at different levels. Under static conditions, the temperature inhomogeneity of the containment amounts to less than $\pm 0.3 \mathrm{~K}$. The inhomogeneity of the aluminium wall temperature, measured with another set of five thermocouples attached to the vessel, was also found to be less than $\pm 0.3 \mathrm{~K}$. Higher temperatures occur only close to a few hot spots around the mechanical feedthrough of a mixing ventilator at the bottom of the vessel and around the air sampling tubes that have to be heated to room temperature during experiments to ensure complete evaporation of particulate water and to minimise vapour adsorption inside the tubes. These hot spots were not considered in calculating the mean aluminium wall temperature $T_{w}$. The mean gas temperature $T_{g}$ represents the average measured by four carefully calibrated thermocouples fixed at different heights on a vertical wire shifted about $1 \mathrm{~m}$ 


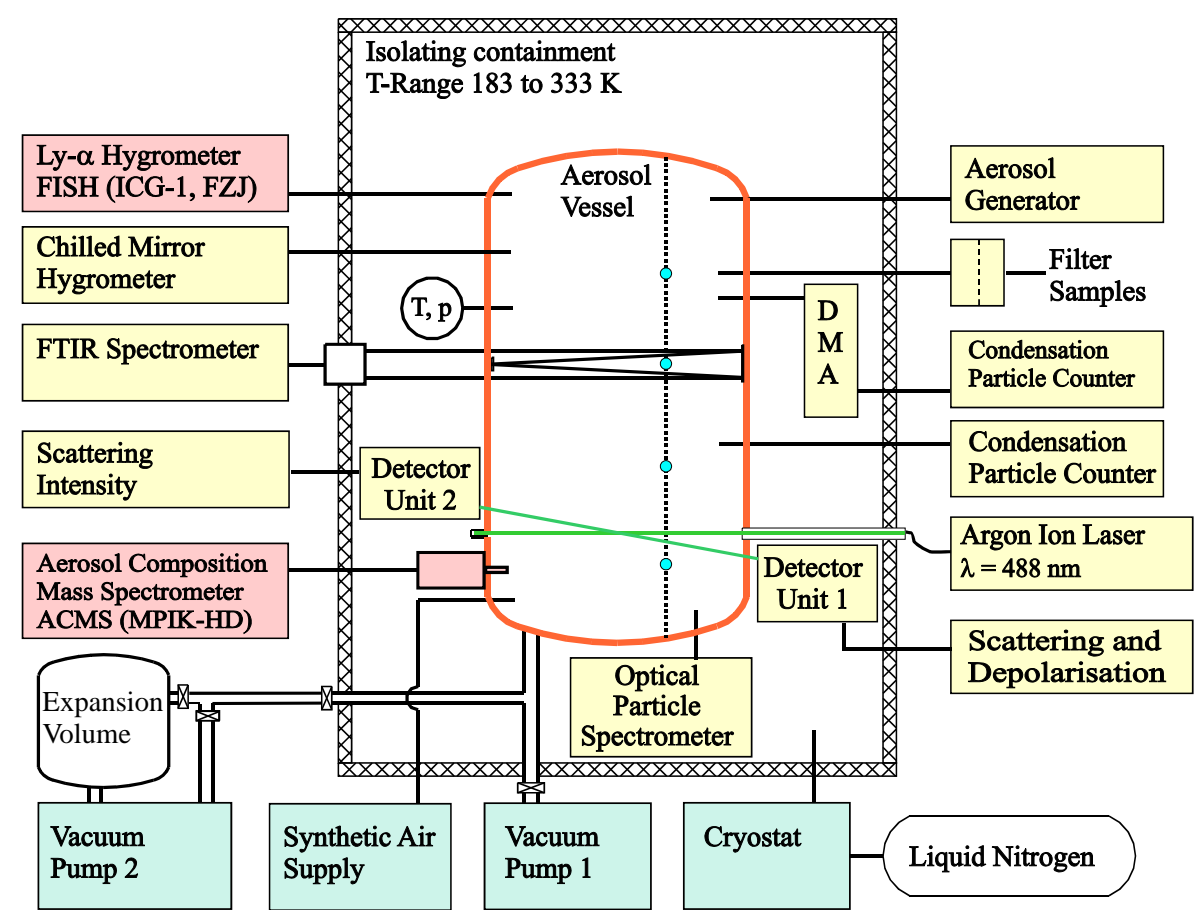

Fig. 1. Schematic view of the AIDA experimental facility showing major technical components and instrumentation used for ice activation experiments. The circles on the dotted line indicate the positions of four thermocouples fixed to a vertical wire which were used to determine the mean gas temperature, $T_{g}$

off the vessel axis, cf. Fig. 1. The response times of these thermocouples to temperature changes during the expansions amounted to about $3 \mathrm{~s}$ at $1000 \mathrm{hPa}, 5 \mathrm{~s}$ at $800 \mathrm{hPa}$, and $10 \mathrm{~s}$ at $180 \mathrm{hPa}$. Due to the hot spots mentioned above, $T_{g}$ was up to $0.8 \mathrm{~K}$ higher than the mean wall temperature $T_{w}$ under conditions of constant pressure. To further homogenise the gas temperature in the vessel, a mixing ventilator was run $1 \mathrm{~m}$ above the vessel floor. This reduced the inhomogeneity to less than $\pm 0.1 \mathrm{~K}$ at constant pressure and to less than $\pm 0.3 \mathrm{~K}$ during expansions with the highest pumping speed of about $400 \mathrm{~m}^{3} \mathrm{~h}^{-1}$.

\subsection{Preparation of experiments}

All ice nucleation (IN) experiments are started at almost ice saturated conditions inside the aerosol chamber. Ice saturation is achieved by (1) cooling the walls to $273 \mathrm{~K}$, (2) evacuating the vessel to $0.01 \mathrm{hPa}$, (3) flushing twice by adding about $5 \mathrm{hPa}$ synthetic air and pumping below $0.01 \mathrm{hPa}$, (4) adding about $3 \mathrm{hPa}$ water vapour into the vessel by evaporating about $210 \mathrm{ml}$ deionised water, (5) filling to atmospheric pressure with dry synthetic air, and (6) slowly cooling the chamber at a rate between -2 and $-4 \mathrm{Kh}^{-1}$ to the starting temperature of the experiment. A water vapour pressure of $3 \mathrm{hPa}$ corresponds to a frost point temperature $T_{f}$ of about $265 \mathrm{~K}$. As soon as the wall temperature drops below $T_{f}$, the excess water vapour is deposited on the vessel walls form- ing a thin ice coating. The ice layer thickness is about $2 \mu \mathrm{m}$ assuming uniform water deposition to the surface of about $110 \mathrm{~m}^{2}$. A series of IN experiments at different temperatures was performed after each ice coating cycle.

Before each individual IN experiment at ice-coated wall conditions, the aerosol vessel is pumped off to a total pressure slightly above the ice saturation pressure at the given temperature and flushed several times with about $5 \mathrm{hPa}$ synthetic air to reduce the background concentration of aerosol particles below $5 \mathrm{~cm}^{-3}$. Pumping below the ice saturation pressure would cause rapid evaporation of the ice coating on the chamber walls. The evacuated chamber is refilled with dry synthetic air to the starting pressure. After refilling is completed as mentioned above, the ice coating establishes a relative humidity RHi with respect to ice between 90 and $95 \%$ within about $30 \mathrm{~min}$ because $T_{g}$ is slightly higher than $T_{w}$ due to heat sources in the chamber (e.g. heated sampling tubes for water measurements).

\subsection{Method of expansion cooling}

In atmospheric clouds, super cooling is induced by expansion and adiabatic cooling of rising air parcels. The cooling rate depends on the adiabatic lapse rate and the updraft velocity. A wide range of atmospheric cooling rates can be simulated in the AIDA aerosol vessel by reducing the pressure with a mechanical pump which can be operated at variable pumping 


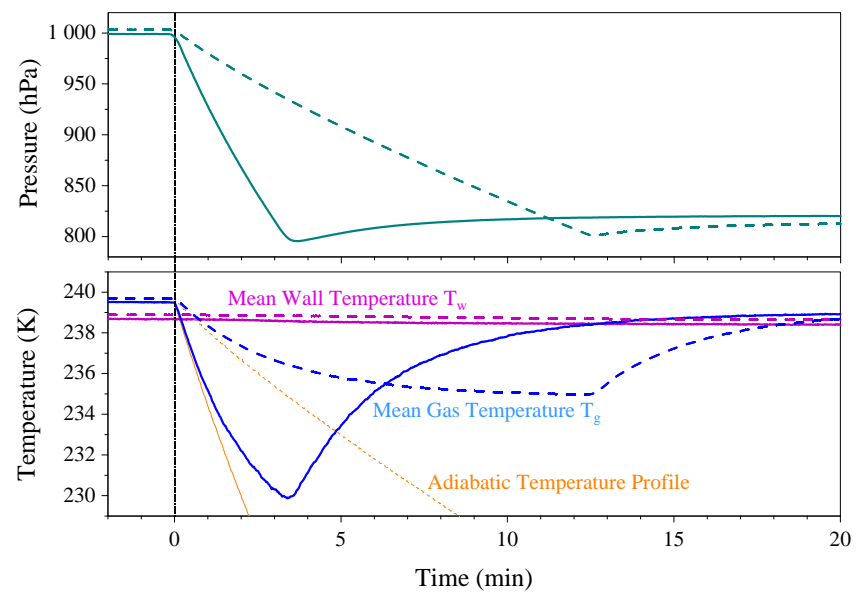

Fig. 2. Variation of pressure and mean gas temperature during pumping from about 1000 to $800 \mathrm{hPa}$ at the maximum pumping speed (solid lines) and a moderate pumping speed (dashed lines). Both expansions were started at about $239.7 \mathrm{~K}$. The adiabatic temperature profile calculated from the pressure decrease is also shown in the lower panel (thin yellow lines).

speeds. Figure 2 shows pressure and associated temperature variations at the highest pumping speed (solid lines) and at moderate pumping speeds (dashed lines). While these expansions would be truly adiabatic in the atmosphere, leading to temperature variations shown by the thin yellow lines in the lower panel of Fig. 2, the cooling rates in the AIDA vessel start to deviate from those of the yellow lines. This is caused by an increasing heat flux from the $2 \mathrm{~cm}$ thick aluminium walls which remain at almost constant temperature during the pumping events due to their high heat capacity. After a pumping period of typically 10 to $15 \mathrm{~min}$ the gas temperature levels off at a dynamic equilibrium value which represents the balance between further expansion cooling and heat flux from the warmer aluminium walls into the gas. Cooling rates and the maximum temperature differences $\Delta T=T_{w}-T_{g}$ increase with increasing pumping speed. At the highest pumping speed (blue solid line in Fig. 2) pumping from $1000 \mathrm{hPa}$ was too rapid to reach the steady-state temperature until the pump was turned off at $800 \mathrm{hPa}$. When pumping is stopped, $T_{g}$ starts to increase and approaches $T_{w}$ within about 10 to $15 \mathrm{~min}$.

As mentioned above, vigorous mixing with the ventilator ensures that the gas temperature is homogeneous within $\pm 0.3 \mathrm{~K}$ throughout the gas volume which is measured by four thermocouples, cf. Fig. 2. Fast temperature fluctuations, however, are partially damped out by the finite response times of the sensors which range between 3 and $10 \mathrm{~s}$, depending on the air pressure. Therefore, larger negative excursions from the mean gas temperature are likely to occur in isolated air parcels (eddies) while they are almost adiabatically cooled. These periods of almost adiabatic cooling must, however, be significantly shorter than the character-

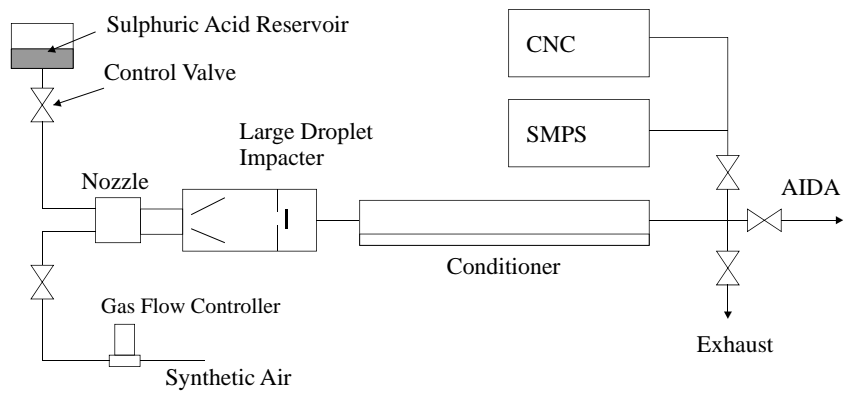

Fig. 3. Sulphuric acid aerosol generator.

istic mixing time of the aerosol vessel, which is about one minute. This effect has to be investigated in future expansion studies using faster temperature sensors. A horizontal line of five temperature sensors close to the vessel wall measured a thickness of the order of a few $\mathrm{cm}$ for the transition layer between the vertical vessel walls and the mixed part of the gas volume. The effect of transport processes across the boundary layer on the concentration and distribution of water vapour will be discussed in Sect. 2.5.

Experimental parameters of all 24 IN experiments conducted within this study are listed in Table 1 . Three series of experiments were conducted in different experimental campaigns during November 2000 (A), July 2001 (B) and November 2001 (C). Sulphuric acid aerosol was added to the vessel only once before a series of expansions of the same aerosol system. The first expansion in such a series is denoted with '_ 1 ' in the experiment number. Second and third expansions of the same aerosol systems are denoted '_2' and '_3', respectively.

During series A, all expansions were started at an initial pressure $p_{0}$ of about $180 \mathrm{hPa}$ because the aerodynamic lens of the aerosol composition mass spectrometer (ACMS, see Sects. 2.4 and 3.3) could not be operated at higher pressures. The start of pumping is taken as reference time $t_{0}$ for all relative times used in the discussion of expansion experiments. In some experiments of series $\mathrm{A}$, the chamber was refilled with dry synthetic air ensuring complete evaporation of the previously formed ice crystals under ice subsaturated conditions. Homogeneous freezing of the residual sulphuric acid aerosol was then investigated in a second expansion.

Experiment series B and $\mathrm{C}$ were made without the ACMS and therefore could be started at higher pressure. During series B, four expansions were performed (experiments B1_1 to B4_1) with starting temperatures between 209 and $226 \mathrm{~K}$ and pumping from about 1000 to $800 \mathrm{hPa}$ (first expansions). The second activations (B1_2 to B4_2) were started at $800 \mathrm{hPa}$ after the ice particles from the first activation had completely evaporated, and were stopped at about $180 \mathrm{hPa}$. This was the starting pressure of the third activations (B1_3 to B3_3), which took place after all ice particles from the previous expansion had evaporated. Conditions of the third activation 
Table 1. Parameters of individual AIDA ice activation experiments. Initial pressures $p_{0}$ and temperatures $T_{0}$ are measured at the reference time $t_{0}$ defined by start of pumping. Further data were measured at the onset time $t_{\text {nuc }}$ of ice formation defined by the increase in the depolarisation signal ( $p_{\text {nuc }}$ : pressure, $T_{g, n u c}$ : mean gas temperature, $T_{f, n u c}$ : frost point temperature, $S_{\text {nuc }}$ : ice saturation ratio, $(d p / d t)_{\text {nuc }}$ : pressure change, $(d T / d t)_{\text {nuc }}=\gamma_{\text {nuc }}$ : cooling rate, $q_{g, n u c}$ : volume mixing ratio of water vapour, $q_{a e, n u c}$ : equivalent volume mixing ratio of aerosol water content, $s_{a e, n u c}$ : equivalent volume mixing ratio of aerosol sulphuric acid content, $w_{S A, n u c}$ : aerosol sulphuric acid weight-\%, $C_{n, n u c}$ : aerosol number concentration, $n_{i}:$ maximum ice number concentration measured with PCS)

\begin{tabular}{|c|c|c|c|c|c|c|c|c|c|c|c|c|c|c|c|}
\hline Exp.No. & $\begin{array}{c}p_{0} \\
\mathrm{hPa}\end{array}$ & $\begin{array}{l}T_{0} \\
\mathrm{~K}\end{array}$ & $\begin{array}{c}t_{\mathrm{nuc}} \\
\mathrm{s}\end{array}$ & $\begin{array}{l}p_{\text {nuc }} \\
\mathrm{hPa}\end{array}$ & $\begin{array}{c}T_{g, n u c} \\
\mathrm{~K}\end{array}$ & $\begin{array}{c}T_{f, \text { nuc }} \\
\mathrm{K}\end{array}$ & $S_{\text {nuc }}$ & $\begin{array}{l}(d p / d t)_{\text {nuc }} \\
\mathrm{hPa} \mathrm{min}^{-1}\end{array}$ & $\begin{array}{c}\gamma_{\text {nuc }} \\
\mathrm{K}_{\min ^{-1}}\end{array}$ & $\begin{array}{l}q_{g, n u c} \\
\text { ppmv }\end{array}$ & $\begin{array}{c}q_{a e, n u c} \\
\text { ppmv }\end{array}$ & $\begin{array}{c}s_{a e, n u c} \\
\mathrm{ppbv}\end{array}$ & $\begin{array}{c}w_{S A, n u c} \\
\text { wt. } \%\end{array}$ & $\begin{array}{l}C_{n, n u c} \\
\mathrm{~cm}^{-3}\end{array}$ & $\begin{array}{c}n_{i} \\
\mathrm{~cm}^{-3}\end{array}$ \\
\hline A1_1 & 182.3 & 194.4 & 270 & 148.1 & 189.4 & 192.6 & $1.73 \pm 0.12$ & -6.0 & 0.09 & 3.5 & 0.38 & 19.97 & 22.2 & 1511 & \\
\hline A1_2 & 179.0 & 194.4 & 198 & 149.3 & 189.2 & 192.6 & $1.77 \pm 0.13$ & -7.2 & -0.50 & 3.4 & 0.16 & 7.69 & 20.8 & 592 & \\
\hline A2_1 & 179.4 & 194.9 & 332 & 138.3 & 189.4 & 192.7 & $1.74 \pm 0.11$ & -6.8 & -0.39 & 3.8 & 0.16 & 8.26 & 21.9 & 1007 & \\
\hline A2_2 & 178.3 & 195.1 & 295 & 142.4 & 190.0 & 193.1 & $1.68 \pm 0.11$ & -6.0 & -0.51 & 3.9 & 0.05 & 2.92 & 23.4 & 417 & \\
\hline A3_1 & 182.2 & 202.2 & 160 & 158.7 & 197.6 & 200.8 & $1.63 \pm 0.10$ & -6.9 & -0.57 & 11.8 & 0.20 & 10.85 & 22.6 & 1223 & 108 \\
\hline A3_2 & 177.9 & 202.2 & 111 & 157.6 & 197.7 & 200.7 & $1.59 \pm 0.10$ & -8.4 & -1.30 & 11.7 & 0.08 & 4.40 & 23.8 & 524 & 130 \\
\hline A4_1 & 180.6 & 204.4 & 211 & 151.9 & 199.5 & 202.8 & $1.65 \pm 0.10$ & -6.4 & -0.39 & 16.5 & 0.63 & 31.42 & 21.3 & 2151 & \\
\hline A5_1 & 176.7 & 212.6 & 127 & 157.0 & 208.2 & 211.1 & $1.48 \pm 0.09$ & -7.2 & -0.88 & 52.7 & 0.18 & 10.09 & 23.3 & 1191 & 42 \\
\hline A6_1 & 180.2 & 222.9 & 105 & 163.5 & 218.6 & 221.3 & $1.40 \pm 0.11$ & -8.1 & -1.06 & 194.4 & 0.32 & 16.57 & 21.8 & 1562 & 15 \\
\hline A6_2 & 178.5 & 222.9 & 573 & 140.7 & 218.4 & 221.0 & $1.41 \pm 0.11$ & -5.3 & -0.44 & 217.9 & 0.17 & 8.72 & 21.9 & 693 & \\
\hline B1_1 & 1001.3 & 208.9 & 190 & 875.2 & 203.3 & 206.5 & $1.61 \pm 0.10$ & -34.3 & -1.00 & 5.0 & 0.74 & 35.45 & 20.8 & 8015 & 50 \\
\hline B1_2 & 817.0 & 208.6 & 136 & 724.5 & 203.2 & 206.7 & $1.65 \pm 0.10$ & -34.7 & -1.19 & 6.2 & 0.79 & 34.76 & 19.4 & 5668 & 50 \\
\hline B1_3 & 178.5 & 208.3 & 118 & 159.1 & 203.8 & 207.1 & $1.61 \pm 0.10$ & -8.2 & -1.13 & 29.7 & 0.41 & 19.46 & 20.6 & 749 & 8 \\
\hline B2_1 & 999.7 & 208.9 & 139 & 902.1 & 204.2 & 207.2 & $1.57 \pm 0.12$ & -35.8 & -1.26 & 5.4 & 0.14 & 7.32 & 22.1 & 1151 & 60 \\
\hline B2_2 & 818.3 & 208.7 & 140 & 734.5 & 203.8 & 207.0 & $1.58 \pm 0.12$ & -31.2 & -1.33 & 6.4 & 0.14 & 7.14 & 21.6 & 882 & 50 \\
\hline B2_3 & 177.2 & 208.4 & 163 & 154.7 & 203.6 & 207.0 & $1.62 \pm 0.10$ & -6.9 & -0.67 & 30.1 & 0.12 & 5.54 & 20.2 & 84 & 15 \\
\hline B3_1 & 991.7 & 219.9 & 129 & 896.9 & 215.0 & 218.4 & $1.56 \pm 0.10$ & -37.8 & -1.65 & 24.4 & 0.73 & 26.63 & 16.5 & 6768 & 30 \\
\hline B3_2 & 813.3 & 219.7 & 101 & 739.4 & 214.9 & 218.3 & $1.56 \pm 0.09$ & -38.7 & -2.16 & 29.4 & 0.73 & 25.99 & 16.3 & 5134 & 25 \\
\hline B3_3 & 178.7 & 218.8 & 121 & 162.2 & 214.5 & 217.9 & $1.55 \pm 0.09$ & -9.5 & -1.79 & 126.3 & 0.68 & 26.05 & 17.2 & 534 & \\
\hline B4_1 & 1002.8 & 225.9 & 261 & 876.6 & 220.7 & 223.9 & $1.50 \pm 0.08$ & -24.3 & -0.43 & 50.2 & 1.09 & 36.09 & 15.2 & 6523 & 8 \\
\hline B4_2 & 811.8 & 225.6 & 96 & 739.5 & 220.7 & 224.0 & $1.49 \pm 0.08$ & -39.7 & -2.17 & 59.5 & 1.03 & 35.67 & 15.9 & 4853 & 30 \\
\hline $\mathrm{C} 1 \_1$ & 997.1 & 235.3 & 72 & 924.1 & 231.0 & 233.7 & $1.37 \pm 0.08$ & -53.2 & -2.75 & 149.3 & 0.48 & 16.95 & 16.2 & 1744 & 40 \\
\hline $\mathrm{C} 1 \_2$ & 975.7 & 235.4 & 83 & 895.9 & 230.6 & 233.3 & $1.39 \pm 0.08$ & -49.9 & -2.55 & 147.9 & 0.47 & 16.11 & 15.7 & 1325 & 35 \\
\hline $\mathrm{C} 1 \_3$ & 982.7 & 235.4 & 79 & 906.4 & 230.8 & 233.7 & $1.40 \pm 0.08$ & -51.6 & -2.53 & 151.5 & 0.41 & 12.10 & 14.0 & 990 & 40 \\
\hline
\end{tabular}

were therefore comparable to series A. All experiments in series $\mathrm{C} 1 \_1$ to $\mathrm{C} 1 \_3$ were carried out with the same sulphuric acid aerosol filling, starting each time at about atmospheric pressure, which required refilling the vessel between subsequent expansions.

\subsection{Aerosol generation and characterisation}

Concentrated sulphuric acid aerosol particles are generated with an apparatus schematically shown in Fig. 3 and added to the aerosol chamber through a stainless steel tube. A $20 \mathrm{wt}$.\% sulphuric acid solution is dispersed in a nozzle using a flow of 10SLM (litres per minute at std. $T, p$ ) at a backing pressure of about 2 bar. Droplets larger than about $1 \mu \mathrm{m}$ in diameter are removed by a single orifice plate im- pactor separating two glass cylinders. The water content of the aerosol is substantially reduced by piping it through a glass tube partly filled with $96 \mathrm{wt} . \% \mathrm{H}_{2} \mathrm{SO}_{4}$. The conditioning tube has a diameter of $2.8 \mathrm{~cm}$ and a length of $560 \mathrm{~cm}$. The residence time of about $20 \mathrm{~s}$ is long enough to achieve almost equilibrium composition between the aerosol particles and the bulk solution (Bunz et al., 2002). At the exit of the conditioner both number concentration and size distribution of the sulphuric acid aerosol is measured with a condensation particle counter (CNC3022, TSI) and a scanning mobility particle sizer (SMPS, TSI). When the concentration and size distribution are within the desired range the aerosol is added to the aerosol vessel. Thereby the aerosol number concentration in the vessel increased at a rate of about $200 \mathrm{~cm}^{-3} \mathrm{~min}^{-1}$. 


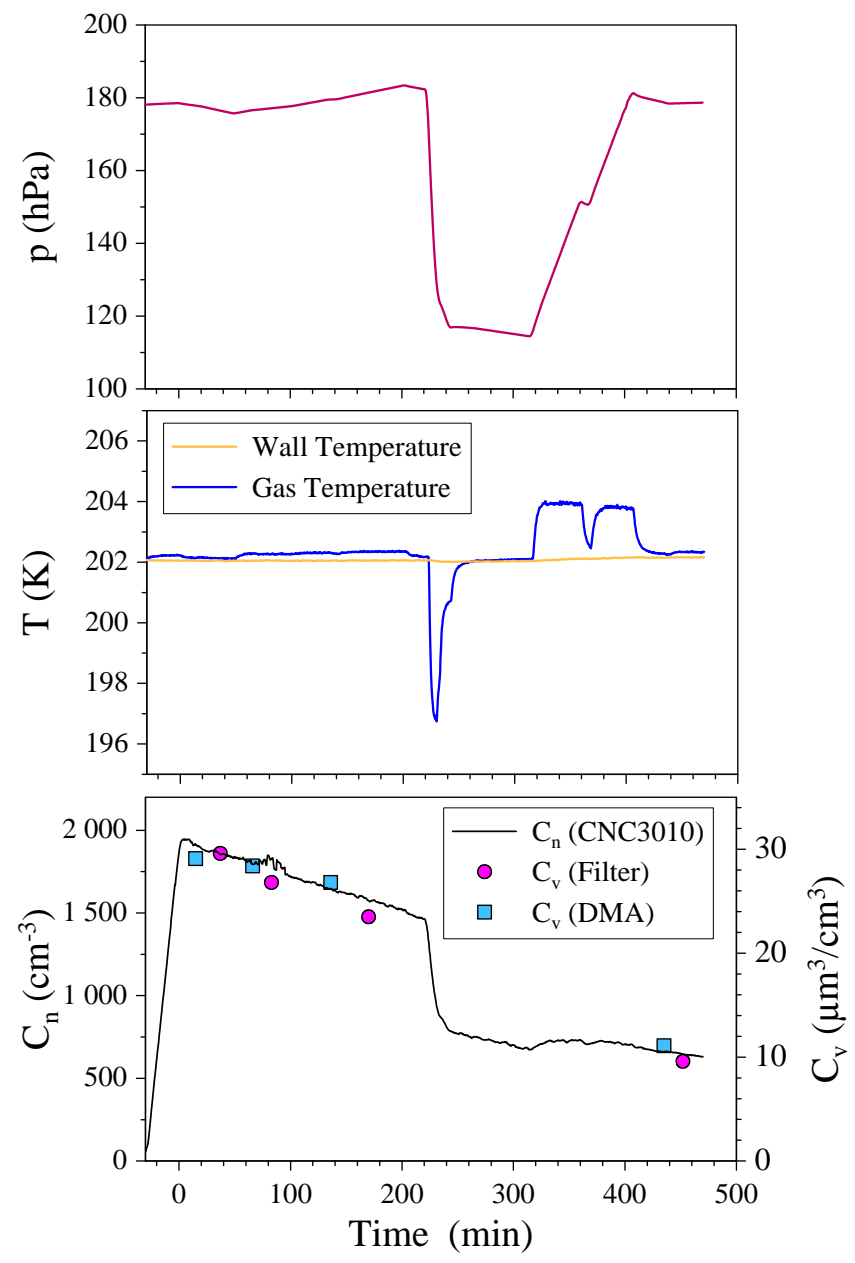

Fig. 4. Pressure, temperatures, aerosol concentrations measured during experiment A3_1. The time axis is set to zero at the end of aerosol addition to the vessel. Pumping started at $t=223 \mathrm{~min}$, the reference time used in Table 1 and Fig. 6.

Aerosol number concentrations at the beginning of the experiments discussed in Sect. 2.3 ranged between about 1000 and $8000 \mathrm{~cm}^{-3}$.

After the highly concentrated sulphuric acid particles are added to the aerosol vessel, they take up water until equilibrium composition with respect to the gas temperature and relative humidity is achieved. Small sample flows of $0.31 \mathrm{~min}^{-1}$ are taken from the aerosol inside the aluminum vessel via stainless steel tubes ( $4 \mathrm{~mm}$ inner diameter) to measure aerosol number concentrations and size distributions with a CNC3010 and a differential mobility analyser (DMA) connected to a second CNC3010 (Fig. 1). The DMA was modified for operation inside the cooled containment at temperatures between $183 \mathrm{~K}$ and room temperatures and pressures between $100 \mathrm{hPa}$ and atmospheric pressure. Operating the DMA at the same temperature as the aerosol vessel avoids evaporation of sulphuric acid particles during size classification. The combination of the modified DMA and the CNC3010 is called low temperature and pressure differential mobility particle sizer (LTP-DMPS). The CNCs are operated at room temperature outside the containment, but had to be modified to sample aerosol at pressures between 100 and $1000 \mathrm{hPa}$. A short transfer time of less than $1 \mathrm{~s}$ into the saturator of the $\mathrm{CNC}$ prevents complete evaporation of particles. This was confirmed by heating the sample tube between the cold box and the CNC incrementally by about 20 to $30 \mathrm{~K}$ above ambient temperature, which had no effect on the particle count rate. Technical details including pressure dependent counting efficiency measurements of the CNC3010 and calibration of the LTP-DMPS will be discussed in a separate paper.

Figure 4 shows pressure, temperature, and aerosol concentration profiles measured during experiment A3_1. This experiment was selected for a detailed modelling study which is presented in a companion paper (Haag et al., 2003), and will also be discussed in more detail in this paper. Note that the time axis in Fig. 4 is plotted relative to the end of aerosol addition to the aluminium vessel at $p=178 \mathrm{hPa}$ and $T_{g}=T_{w}=202 \mathrm{~K}$. The pressure underwent only minor changes between $t=0$ and $t=223 \mathrm{~min}$. Then the pressure was sharply reduced by mechanical pumping to induce ice nucleation. This time is used as reference time $t_{0}$ in Table 1 and Fig. 6. During the first 223 min of almost constant $p, T_{g}$, and $T_{w}$, the aerosol number concentration $C_{n}$ (solid black line in the lower panel) decreased slowly from 1850 to $1600 \mathrm{~cm}^{-3}$, mainly due to sedimentational losses of larger particles (coagulation is of minor importance at these low number concentrations). The sharp decrease of $C_{n}$ after $t=223 \mathrm{~min}$ is almost completely due to particle removal by pumping from 183 to $115 \mathrm{hPa}$. Furthermore, the pressure dependent counting efficiency correction of the CNC3010 data may slightly underestimate the number concentrations at low pressures.

Ion chromatographic analysis of nylon filter samples yields total aerosol sulphuric acid mass concentrations, $C_{m, S A}$. Assuming thermodynamic equilibrium composition of the particles, aerosol mass concentrations $C_{m, S A}$ can be converted into aerosol volume concentrations $C_{v}$, which are also shown in the lower panel of Fig. 4 (solid circles, right axis) together with volume concentrations (squares) derived from size distribution measurements (see below). Clearly, the decrease in aerosol volume parallels the decrease in number concentration within experimental uncertainty. Therefore, the continuous $C_{n}$ data set could be used to interpolate aerosol volume concentrations between the filter samples.

Figure 5 shows size distributions measured with the LTPDMPS under nearly ice saturated conditions during experiment A3_1 about 15, 76, 146, and 435 min after aerosol addition to the vessel. Particle diameters are in the range of 50 to $1000 \mathrm{~nm}$ which is close to the size range of sulphuric acid particles in the stratosphere. The size distribution changed only slightly during the expansion and refilling cycle. Total aerosol volumes were obtained by integrating the volume- 


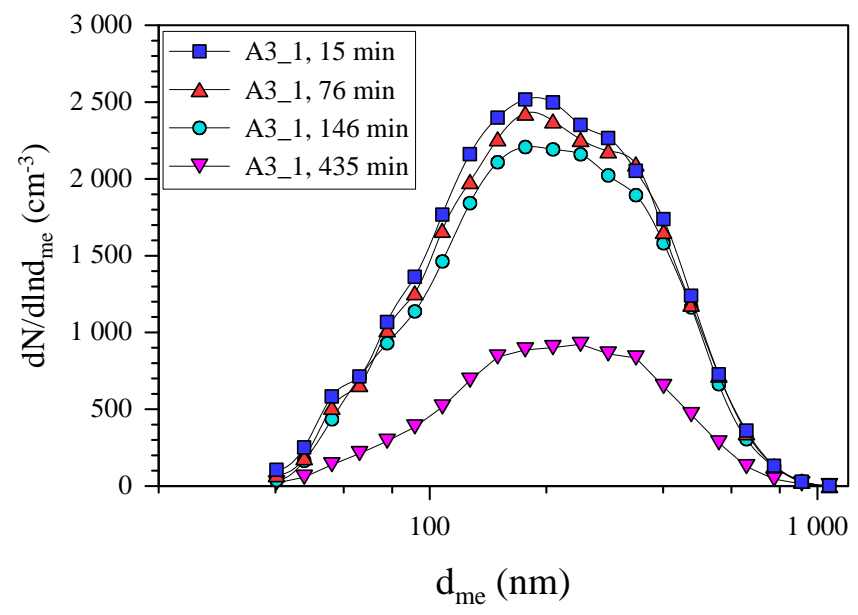

Fig. 5. Typical number size distribution of sulphuric acid aerosol added to the AIDA chamber at the beginning of experiment A3_1. The measurements were made with the LTP-DMPS at a pressure of $180 \mathrm{hPa}$ and a temperature of $202 \mathrm{~K}$.

weighted size distributions shown in Fig. 5. The results, filled squares in Fig. 4, agree well with the filter data.

\subsection{Water measurements and ice saturation ratio}

Figure 6 shows experimental data measured during the expansion cycle of experiment A3_1. Pressure and temperature profiles are the same as in Fig. 4, however, the time is now plotted relative to the starting time $t_{0}$ of pumping (see Sect. 2.3). The pressure was reduced at three different pumping speeds from 183 to $115 \mathrm{hPa}$ within a time period of about $1320 \mathrm{~s}$ (panel a). As explained in Sect. 2.3, $T_{g}$ steeply decreases after $t_{0}$ and levels off after about 5 min of pumping, which is somewhat earlier than during the expansions shown in Fig. 2 due to the lower pressure. Thereafter, the temperature stepwise increases with decreasing pumping speed.

Water vapour mixing ratio (panel c in Fig.6) is measured with the fast in situ Lyman- $\alpha$ hygrometer (FISH) of Forschungszentrum Jülich (Zöger et al., 1999) which is, however, run as an ex situ instrument during the AIDA experiments (Fig. 1). The FISH was calibrated against a high precision frost point hygrometer (MBW DP30). Under constant $p, T$-conditions in the aerosol vessel the calibrated FISH agreed well with another commercial chilled mirror hygrometer from General Eastern (type 1311 DR-XP) which was used to measure water vapour in the aerosol vessel. This instrument was, however, sensitive to sulphuric acid aerosol deposition on the frost point mirror, which had to be cleaned at regular intervals, and provided only limited information during dynamic expansions because its response time on changing pressure and humidity conditions is too long. The FISH instrument measures with a time resolution of $1 \mathrm{~s}$ providing almost immediate response to changing water mixing ratios. The overall accuracy is about $6 \%$ with a detection

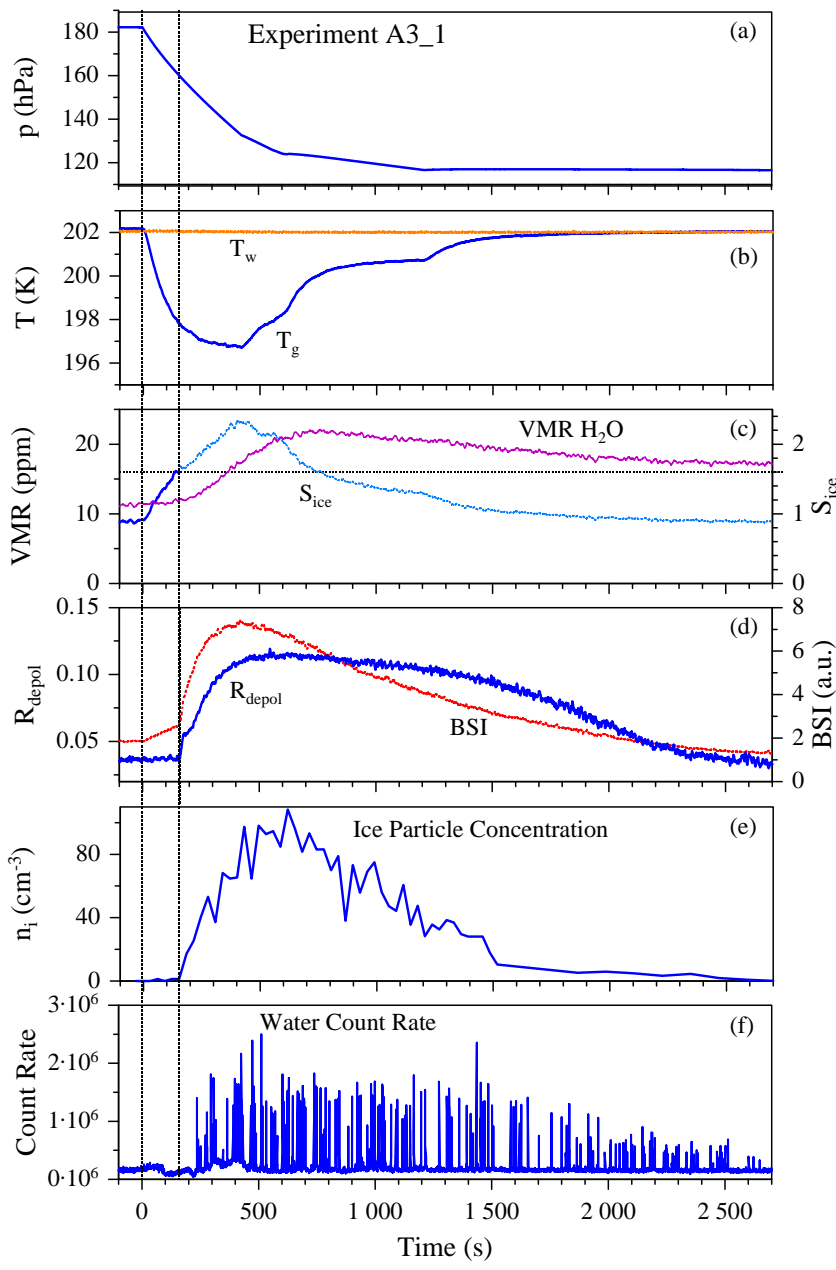

Fig. 6. Data plots of experiment A3_1. The panels show pressure $p$, mean gas and wall temperature, water volume mixing ratio and ice saturation ratio evaluated with total water, depolarisation ratio and back-scatter intensity, number concentration of ice particles, and water count rates of the aerosol mass spectrometer.

limit of about $0.2 \mathrm{ppm}$. This refers to a typical pressure of about 60 to $70 \mathrm{hPa}$ in the measuring cell. The corresponding detection limits for water vapour in the aerosol chamber are about $0.004 \mathrm{~Pa}$ at $180 \mathrm{hPa}$ total pressure and $0.02 \mathrm{~Pa}$ at $1000 \mathrm{hPa}$ total pressure. The sampling flow rates of the FISH and chilled mirror hygrometer are about $51 \mathrm{~min}^{-1}$ and $2.51 \mathrm{~min}^{-1}$, respectively. The air was sampled through a stainless steel tube of $8 \mathrm{~mm}$ inner diameter heated to $40^{\circ} \mathrm{C}$. Therefore, the recorded water signal corresponds to total (= gas + condensed phase) water, since ice and liquid aerosol particles are rapidly evaporated in the heated sampling tube. The sampling efficiency of ice particles was estimated to be almost $100 \%$ for particle diameters up to $7 \mu \mathrm{m}$. The sampling efficiency decreases for larger particles. Therefore, the FISH measurement underestimates the total water concentration if ice particles larger than $7 \mu \mathrm{m}$ in diameter are present 
in the chamber.

The total water volume mixing ratio measured during experiment A3_1 is shown in panelc of Fig. 6. In absence of any sources of water, the mixing ratio should be constant during pumping. However, the mixing ratio is rising after some time of pumping. This is due to the fact that the wall temperature and therefore the water vapour pressure above the ice coated wall is almost constant during pumping, whereas the water vapour pressure inside the vessel is decreasing with decreasing total pressure. The resulting concentration gradient drives a water vapour flux through the boundary layer into the well mixed vessel volume. The time scale for this transport process is of the same order as for the heat flux described in Sect. 2.3. After the onset of ice nucleation, e.g. detected by the depolarisation increase of back-scattered laser light (panel d, cf. Sect. 3) the interstitial water vapour pressure is further reduced by uptake onto the ice particles formed in a highly supersaturated environment. This causes an increase of the concentration gradient in the wall transition region and therefore an additional increase in the total water mixing ratio. The ice particles continue to grow by this source of water vapour as long as the gas temperature is significantly lower than the wall temperature. The decrease of water volume mixing ratio before $T_{g}$ approaches $T_{w}$ (cf. panels b and c of Fig. 6) may be due to undersampling as well as depositional losses of larger ice particles. In previous cloud chamber studies this wall effect was minimised by controlled lowering of the wall temperature during pumping (DeMott et al., 1990). This technique could not be applied in our experiments because the AIDA chamber has a surface area of ca. $100 \mathrm{~m}^{2}$. Controlled and homogeneous cooling of such a large area is not possible at the required rate.

As long as no ice particles are present, the ice saturation ratio $S_{\text {ice }}$ can be calculated from the total water mixing ratio $q_{t}$ measured with the FISH instrument, the aerosol water content $q_{a e}$ calculated from the filter sulphuric acid data assuming equilibrium composition of the sulphuric acid aerosol, the gas pressure $p$, and the ice saturation pressure $p_{w}$,ice

$S_{\text {ice }}=\frac{p_{w}}{p_{w, i c e}}=\frac{\left(q_{t}-q_{a e}\right) p}{p_{w, i c e}}$

where $p_{w}$ is the partial pressure of water vapour. The saturation vapour pressure over ice is calculated from $T_{g}$ according to Marti and Mauersberger (1993). As discussed in the companion paper, the aerosol composition slightly deviates from thermodynamic equilibrium during pumping. However, the assumption of equilibrium had only a minor affect on calculating $S_{\text {ice }}$ because the sulphuric acid aerosol contained only a minor fraction of total water at the nucleation threshold (cf. Table 1). Panel c of Fig. 6 shows $S_{\text {ice }}$ calculated for experiment A3_1. It should be noted that calculating $S_{\text {ice }}$ with the above formula is only valid until ice particles are formed at the onset time for ice nucleation, $t_{\text {nuc }}$. Shortly after $t_{\text {nuc }}$, the nucleated ice particles start takeing up a significant fraction of total water in the aerosol vessel. The total water measurements cannot directly be corrected for the ice water content $q_{\text {ice }}$ because no direct measurements of $q_{\text {ice }}$ are available. A modelling approach to treat the partitioning of water between the gas and ice phases is discussed in the companion paper (Haag et al., 2003).

\section{Ice particle detection}

During expansion experiments the formation of ice particles is detected by three independent methods: (1) backscattered intensity and depolarisation measurements, (2) single large particle counting, and (3) chemical composition measurements with an aerosol composition mass spectrometer (ACMS).

\subsection{Depolarisation of back-scattered laser light}

To measure intensity and depolarisation of back-scattered laser light with high sensitivity and time resolution, an Argon-Ion laser beam ( $99 \%$ polarised light at $488 \mathrm{~nm}$ ) is directed into the chamber via an optical fibre which preserves the plane of polarization (Fig. 1). The laser beam and the aperture of the detection optics at $176^{\circ}$ scattering angle overlap in the middle of the chamber at a distance of $2 \mathrm{~m}$ from the walls, providing about $2 \mathrm{~cm}^{3}$ of scattering volume. The scattered light is split into the parallel and the perpendicular components by a Glan-Taylor prism and then detected by two independent photomultipliers in the photon counting mode using an integration time of $1 \mathrm{~s}$. A second optical detector is mounted in the forward direction at a scattering angle of $4^{\circ}$, measuring total scattering intensity with a single photomultiplier. Panel d of Fig. 6 depicts depolarisation ratios $R_{\text {depol }}$ and back-scattered intensities BSI measured during experiment $\mathrm{A} 3_{-}{ }_{1}$. The depolarisation ratio is defined as $R_{\text {depol }}=B S I_{\perp} /\left(B S I_{\perp}+B S I_{\|}\right)$where $B S I_{\perp}$ and $B S I_{\|}$are the backscattered intensities in the planes perpendicular and parallel to the polarisation plane of the incident laser beam. The total BSI is simply the sum of both channels, plotted in arbitrary units in Fig. 6.

The different regimes of a typical IN experiment can clearly be recognized in the plots of $R_{\mathrm{depol}}$ and $B S I$ : (1) Under static conditions before pumping, $B S I$ of the sulphuric acid aerosol in the vessel is almost constant and $R_{\text {depol }}$ shows a constant background value of about 0.03 due to Raleigh scattering by air molecules and a background of light reflected from the aluminium chamber walls. (2) Immediately after the onset of pumping the sulphuric acid particles grow by water uptake due to increasing relative humidity and therefore the $B S I$ signal increases. $R_{\text {depol }}$ does not change because the particles remain liquid. (3) The onset time $t_{\text {nuc }}$ of ice formation is determined by the sharp increase of $R_{\text {depol }}$. The $B S I$ also sharply increases after $t_{\text {nuc }}$ due to faster growth of ice particles compared to the liquid particles. (4) With 
decreasing pumping speed and increasing gas temperature both $R_{\text {depol }}$ and $B S I$ decrease because particles deposit to the chamber walls. (5) With $T_{g}$ approaching $T_{w}$ after pumping is stopped, the ice particles completely evaporate at $S_{\text {ice }} \leq 1$ and $R_{\text {depol }}$ drops back to the background level.

An interesting feature of the $R_{\text {depol }}$ profile is the very sharp increase of the signal at $t_{\text {nuc }}=160 \mathrm{~s}$, followed by a transient levelling off before the depolarisation signal starts to rise again sharply about $50 \mathrm{~s}$ after $t_{\text {nuc }}$. We speculate that the first sharp increase is due to spontaneous freezing of a small fraction of the supercooled liquid aerosol particles when the nucleation threshold is reached. This idea is supported by the evolution of the modelled ice particle number distributions, as discussed in Sect. 4.4 of the companion paper (Haag et al., 2003, see Fig. 8). The second rise in the depolarisation signal is due to the subsequent ice crystal growth as water vapour is replenished by evaporation from the ice-coated chamber walls.

\subsection{Optical particle counter}

Number concentrations and optical sizes of growing ice particles are measured with an optical particle spectrometer (PCS2000, Palas) mounted below the aerosol vessel (Fig. 1). The major part of the sampling tube has the same temperature as the aerosol vessel wall to avoid ice particle evaporation during sampling. The spectrometer measures particles with diameters between about 0.5 and $20 \mu \mathrm{m}$ in 128 size bins. Before $t_{\text {nuc }}$ no particles are detected in the size bins larger than about $1.5 \mu \mathrm{m}$ optical diameter, and all pulses detected above this threshold during an expansion experiment can clearly be attributed to ice particles that were grown to optical diameters larger than $1.5 \mu \mathrm{m}$. However, smaller ice particles cannot be distinguished from liquid sulphuric acid droplets. The time resolution of PCS2000 measurements was $30 \mathrm{~s}$ during experiment series $\mathrm{A}$ and $\mathrm{B}$ and $1 \mathrm{~s}$ during experiment series $\mathrm{C}$. These measurements are also quite sensitive for detecting the onset of ice nucleation.

The overall count rate above $1.5 \mu \mathrm{m}$ can be converted into a number concentration of ice particles, $n_{i}$, larger than this size (Fig. 6, panel e). Maximum $n_{i}$ measured during each experiment are listed in Table 1. Comparison of the last two columns reveals that the fraction of frozen aerosol particles detected with the optical particle spectrometer was extremely variable, between 0.1 (B4_1) and 25\% (A3_2). The increase of the ice particle number count may be delayed due to partial evaporation of ice crystals in the slightly warmer sampling tube. Furthermore, the sampling efficiency is less than $100 \%$ for particles with mean diameters larger than about $10 \mu \mathrm{m}$ (Davies, 1968). Because the ice crystal size and habit was not measured in the present experiments the sampling efficiency could not be determined. Therefore the ice crystal number concentrations $n_{i}$ must be considered as lower limits, in particular for experiments at higher temperatures where ice crystal growth is very rapid.

\subsection{Aerosol composition mass spectrometer}

The aerosol composition mass spectrometer (ACMS) of Max-Planck-Institut für Kernphysik, Heidelberg (Schreiner et al., 2002; Zink et al., 2002), was used to quantitatively measure the water and sulphuric acid contents in aerosol particles. Aerosol is sampled directly from the AIDA vessel through an aerodynamic lens system forming a narrow particle beam. The particle beam is directed through a capillary separating two cryogenically pumped vacuum chambers. The gas molecules, however, expand behind the lens and are efficiently pumped off in the first chamber. This results in a gas phase suppression factor of about $10^{5}$. In the second chamber, the aerosol beam impinges on a gold target in the middle of a gold-plated sphere heated to about $370 \mathrm{~K}$. The impinging particles evaporate and the volatile constituents are detected by a quadrupole mass spectrometer with an electron impact ionisation source. The instrument was calibrated for aerosol sulphuric acid and water content using aerosols from a well defined laboratory calibration source (Knopf et al., 2001).

A continuous flow of a large number of small sulphuric acid solution droplets establishes steady state count rates of water and sulphuric acid mass peaks that can be converted into an aerosol molar ratio of water to sulphuric acid using the calibration results. In a previous study of supercooled liquid sulphuric acid aerosol particles in the AIDA chamber (Zink et al., 2002), the ACMS results were shown to agree with the expected thermodynamic equilibrium composition over a wide range of temperatures and total water vapour mixing ratios, which were measured with the FISH instrument as desribed in Sect. 2.5 above. Those measurements were made over time periods of up to two days with only slight changes of the aerosol mass concentration. During the pumping periods of the present experiments, the aerosol mass concentration decreased by about $20 \%$ within a few minutes. Therefore, the sulphuric acid aerosol content measured with the ACMS during expansion experiments is overestimated due to memory effects of sulphuric acid inside the evaporation sphere of the ACMS.

Fortunately, the response time to changing aerosol concentrations is much faster for water than for sulphuric acid. Therefore, the water signal, mainly represented by the count rate of mass 18 plotted in panelf of Fig. 6, can be used as a sensitive detector for growing ice particles. The peaks in the water signal are due to single large ice particles hitting the evaporation target in the gold sphere. The slight delay between the nucleation onset as determined by the depolarisation and PCS measurements and the first single large ice particle peak seen by the ACMS may be caused by sampling statistics (note that the volume flow rate into the aerodynamic lens was only $5 \mathrm{ml} \mathrm{s}^{-1}$ ). Furthermore, ice particles may need to grow beyond a critical size to be detected as individual particles above the continuous background of liquid aerosol particles. This would be in keeping with the delayed growth 
Table 2. Comparison of ice particle detection times measured with different ice detectors (depol: depolarisation of back-scattered laser light; PCS: optical particle counter; ACMS: Aerosol composition mass spectrometer)

\begin{tabular}{ccccc}
\hline Exp.No. & \multirow{2}{*}{$T_{0}[\mathrm{~K}]$} & \multicolumn{3}{c}{$t_{\text {ice }}[\mathrm{s}]$} \\
\cline { 3 - 5 } & & Depol & PCS & ACMS \\
\hline A1_1 & 194.4 & $270 \pm 80$ & & $306 \pm 30$ \\
A1_2 & 194.4 & $198 \pm 24$ & & $103 \pm 30$ \\
A2_1 & 194.9 & $332 \pm 2$ & & $282 \pm 30$ \\
A2_2 & 195.1 & $295 \pm 10$ & & $390 \pm 30$ \\
A3_1 & 202.2 & $160 \pm 2$ & $167 \pm 30$ & $206 \pm 30$ \\
A3_2 & 202.2 & $111 \pm 5$ & $140 \pm 15$ & $125 \pm 30$ \\
A4_1 & 204.4 & $211 \pm 10$ & & $224 \pm 30$ \\
A5_1 & 212.6 & $127 \pm 2$ & $139 \pm 15$ & $103 \pm 30$ \\
A6_1 & 222.9 & $105 \pm 2$ & $98 \pm 15$ & $116 \pm 30$ \\
A6_2 & 222.9 & $573 \pm 5$ & & $599 \pm 30$ \\
\hline B1_1 & 208.9 & $190 \pm 10$ & $212 \pm 30$ & \\
B1_2 & 208.6 & $136 \pm 5$ & $139 \pm 15$ & \\
B1_3 & 208.3 & $118 \pm 5$ & $157 \pm 15$ & \\
B2_1 & 208.9 & $139 \pm 15$ & $170 \pm 15$ & \\
B2_2 & 208.7 & $140 \pm 15$ & $153 \pm 15$ & \\
B2_3 & 208.4 & $163 \pm 15$ & $154 \pm 15$ & \\
B3_1 & 219.9 & $129 \pm 10$ & $136 \pm 15$ & \\
B3_2 & 219.7 & $101 \pm 3$ & $108 \pm 15$ & \\
B3_3 & 218.8 & $121 \pm 3$ & & \\
B4_1 & 225.9 & $261 \pm 10$ & $244 \pm 30$ & \\
B4_2 & 225.6 & $96 \pm 2$ & $105 \pm 15$ & \\
\hline C1_1 & 235.3 & $72 \pm 5$ & $75 \pm 5$ & \\
C1_2 & 235.4 & $83 \pm 3$ & $83 \pm 3$ & \\
C1_3 & 235.4 & $79 \pm 3$ & $77 \pm 3$ & \\
\hline & & & & \\
\hline
\end{tabular}

of frozen particles, which was discussed in the last paragraph of Sect. 3.1. For these reasons, a rough estimate of the uncertainty in measuring $t_{\text {nuc }}$ with the ACMS, last column in Table 2, is $30 \mathrm{~s}$.

\section{Ice nucleation results}

\subsection{Evaluation of $S_{\text {nuc }}$}

The ice particle detection times obtained by depolarisation measurements (depol), optical particle counting (PCS), and fast water detection (ACMS) as described in Sect. 3 are summarized in Table 2. For the ACMS, $t_{\text {ice }}$ is defined as the time where the first water spike was detected. The depolarisation measurement turned out to be most sensitive to the formation of ice particles. Therefore, this time is taken as the freezing onset time $t_{\text {nuc }}$. Hereafter, the index ' $n u c$ ' refers to measurements at $t_{\text {nuc }}$. The freezing onset time $t_{\text {nuc }}$ is defined as the intersection between a horizontal line fitting the background signal and a tangent to the steeply rising depolaristion signal (Fig. 6, panel d). The uncertainty for $t_{\text {nuc }}$ typically varies between \pm 2 and $\pm 15 \mathrm{~s}$. The time resolution of PCS measurements is limited by the integration time of $30 \mathrm{~s}$ during experiment series A and B. As mentioned above, PCS data were recorded at a rate of $1 \mathrm{~Hz}$ during series $\mathrm{C}$. ACMS measurements are only available for experiment series A. There is good agreement between PCS, ACMS, and depolarisation measurements of $t_{\text {ice }}$.

Table 1 gives besides other parameters the pressures $p_{\text {nuc }}$, gas temperatures $T_{\mathrm{g}, \text { nuc }}$, and ice saturation ratios $S_{\text {nuc }}$. Until $t_{\text {nuc }}$, the decrease in gas temperature $T_{\text {nuc }}-T_{0}$ is about -4 to $-5 \mathrm{~K}$. Because the decrease in water vapour pressure during pumping from $p_{0}$ to $p_{\text {nuc }}$ is only partially compensated by ice evaporating from the chamber walls, the frost point temperature $T_{\mathrm{f} \text {,nuc }}$ calculated from the measured water vapour concentration also decreases by about 1.5 to $2.0 \mathrm{~K}$ compared to $t_{0}$. Therefore, supercooling with respect to ice saturation at $t_{\text {nuc }}$ is only about 2 to $3 \mathrm{~K}$. The corresponding ice saturation ratio $S_{\text {nuc }}$ is plotted in Fig. 7 vs. $T_{\mathrm{g}, \text { nuc }}$. As discussed in Sect. 2.5, $S_{\text {nuc }}$ was calculated using the total water concentration $q_{\mathrm{t} \text {,nuc }}$ corrected for the aerosol water content $q_{\text {ae,nuc }}$. Equilibrium conditions where assumed to calculate $q_{\text {ae,nuc }}$ with the AIM thermodynamic model (Carslaw et al., 1995; Clegg et al., 1998) which is available via the world wide web (http://mae.ucdavis.edu/wexler/aim). The model input parameters $p_{\text {nuc }}, T_{\mathrm{g}, \mathrm{nuc}}, q_{\mathrm{t}, \mathrm{nuc}}$, and aerosol sulphuric acid concentration $s_{\mathrm{ae}, \text { nuc }}$ are also listed in Table 1. In all experiments, the aerosol water content was only a minor fraction of $q_{\mathrm{t}, \text { nuc }}$. Therefore, the correction had only a small effect on $S_{\text {nuc. }}$.

Circles in Fig. 7 show the first and second activations of series A, both started at about $180 \mathrm{hPa}$. Filled up-triangles, open up-triangles, and open down-triangles mark subsequent activations of the same aerosol in series $\mathrm{B}$ which were started at $1000 \mathrm{hPa}, 800 \mathrm{hPa}$, and $180 \mathrm{hPa}$, respectively. That is, only the latter ones are started at the same pressure as experiments A. In experiments A and B, freezing occurred at cooling rates between almost 0 and $-2.2 \mathrm{~K} \mathrm{~min}^{-1}$ with aerosol number concentrations in the range of 84 to $8000 \mathrm{~cm}^{-3}$. Three subsequent activations of series $\mathrm{C}$ (filled diamonds) were made at almost the same thermodynamic conditions (e.g. $p_{0}, T_{0}, \gamma_{\text {nuc }}$ ) but with the aerosol concentration decreasing from experiment to experiment due to dilution (see Sect. 2.4). In these experiments, the highest cooling rates of about $-2.6 \mathrm{~K} \mathrm{~min}^{-1}$ were applied.

In general, $S_{\text {nuc }}$ markedly increases with decreasing gas temperature from about 1.4 at $230.8 \mathrm{~K}$ to about 1.75 at $189.3 \mathrm{~K}$. There is good agreement between the data of the different experiment series. Uncertainties of $S_{\text {nuc }}$ shown in Fig. 7 are calculated from the uncertainties of $T_{\mathrm{g}, \text { nuc }}$ $( \pm 0.3 K), q_{\text {nuc }}( \pm 6 \%)$, and $t_{\text {nuc }}$ (see Table 1$)$. The largest 


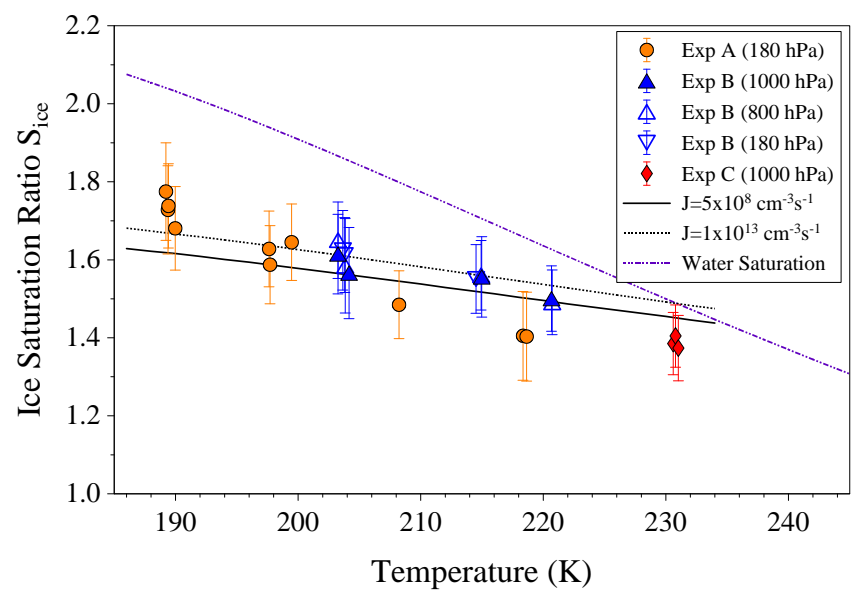

Fig. 7. Ice saturation ratio $S_{\text {nuc }}$ measured at onset of ice formation, $t_{\text {nuc }}$, as function of temperature $T_{g, n u c}$. The data points are grouped according to the different experiment series and to subsequent activations of experiments B (cf. Table 1). The data points are compared to the activity parameterisation by Koop et al. (2000) calculated for nucleation rates of $5 \cdot 10^{8} \mathrm{~cm}^{-3} \mathrm{~s}^{-1}$ (solid line) and $10^{13} \mathrm{~cm}^{-3} \mathrm{~s}^{-1}$ (dashed line). The liquid water saturation line (dash-dotted) was calculated using the parameterisation given by Tabazadeh et al. (1997b).

contribution is due to the uncertainty in $T_{\text {nuc }}$ because $(\partial \ln S / \partial T)_{p}=\Delta H /\left(R T^{2}\right)$ shows a square dependence on temperature $(\Delta H=$ enthalpy of sublimation of ice, taken from Marti and Mauersberger (1993)). For experiments A6_1 and A6 2, a somewhat larger statistical error of $\pm 10 \%$ was estimated for $q_{\text {nuc }}$ because the FISH had been calibrated in the range 5 to $100 \mathrm{ppm}$, and this calibration curve had to be extrapolated to determine exceptionally large mixing ratios of about $200 \mathrm{ppm}$ in these experiments. When the air is cooled at the lowest temperatures an additional systematic increase is introduced due to a non-equilibrium effect which is modelled in the companion paper (Haag et al., 2003). Large supercooled liquid particles do not reach their equilibrium water activity due to the small absolute amount of water vapour available in the gas phase, and thus do not freeze at the thermodynamic threshold temperature $T_{g}$. Furthermore, as was outlined in Sect. 2.3, there may be a systematic bias in $t_{\text {nuc }}$ because of temperature fluctuations around $T_{g}$, i.e. early freezing in air parcels (eddies) in which the local cooling rate may approach the true adiabatic cooling rate (= slopes of the dashed lines in Fig. 2) for short periods of time.

The data points of series A follow a steeper slope compared to series B. At least part of the steeper slope is due to the size and temperature dependent non-equilibrium effects discussed above and in the companion paper. At the highest temperature in series A (experiments A6_1 and A6_2) the freezing onset occurred at a lower saturation ratio compared to the later experiment series B. Because the background aerosol concentration was unusually high during these exper- iments (about $10 \mathrm{~cm}^{-3}$ even after pumping off to $10 \mathrm{hPa}$ and refilling with synthetic air), it cannot be totally ruled out that freezing was affected by heterogeneous nucleation. In subsequent experiments, particularly in series $\mathrm{B}$ and $\mathrm{C}$, care was taken to keep the particle number density below $5 \mathrm{~cm}^{-3}$. The effect of this background aerosol was tested in several reference experiments which were carried out with typical cooling rates and ice supersaturations, but without adding sulphuric acid aerosol to the vessel. It was found that the changes in depolarisation signal and ice particle number count due to the background aerosol were always too low to interfere with the detection of $t_{\text {nuc }}$ in the presence of sulphuric acid aerosol.

\subsection{Critical nucleation rates}

The estimate of critical nucleation rates is based on the analysis of the initial increase of the depolarisation signal during the nucleation peak. About 100 particles per $\mathrm{cm}^{3}$ freeze in experiment A3_1. As proposed in Sect. 3.1, we surmise that the first short plateau in the depolarisation trace, paneld in Fig. 6, marks the time when this number of particles have frozen, while the second steep increase of the signal trace is due to changing shape of the growing particles. We can estimate from the depolarisation trace that the detection threshold corresponds to about 30 out of 100 particles being frozen, i.e. to a freezing probability $P_{\text {crit }} \sim 0.3$.

To deduce the critical nucleation rate $J_{\text {crit }}$ we use the following formula with $V_{p}=$ volume of the particles which freeze

$P_{\text {crit }}=1-\exp \left(-J_{\text {crit }} V_{p} \Delta t\right)$

or, in terms of the critical nucleation rate:

$J_{\text {crit }}=-\frac{\ln \left(1-P_{\text {crit }}\right)}{V_{p} \Delta t}$

Note that, strictly speaking, $J_{\text {crit }}$ is only defined for particles with similar $V_{p}$. An estimate of $V_{p}$ is given in the companion paper where it is shown that most of the particles which freeze in experiment A3_1 are approximately $1 \mu \mathrm{m}$ in diameter (cf. Haag et al., 2003, Fig. 8, top panel), i.e. have a volume of $\sim 5 \cdot 10^{-13} \mathrm{~cm}^{3}$. This yields $J_{\text {crit }} \sim 3 \cdot 10^{11} \mathrm{~cm}^{-3} \mathrm{~s}^{-1}$.

An uncertain parameter in the estimate of the nucleation rate is $V_{p}$ which is not well defined when particles of different sizes are activated at high cooling rates. For the different experiments, the diameters of freezing particles may range from 0.5 to $2 \mu \mathrm{m}$ with respective volumes of $\sim 6 \cdot 10^{-14}$ to $\sim 4 \cdot 10^{-12} \mathrm{~cm}^{3}$. The exact estimate of $P_{\text {crit }}$ has little influence on $J_{\text {crit }}$ as long as we can be sure that significantly less than the maximum number of frozen particles can be detected, which seems to be justified for the depolarisation measurements. Because the backscattering measurement is sensitive to the total number concentration of frozen particles, lower fractions of frozen particles can be detected at higher aerosol number concentrations. Therefore, $P_{\text {crit }}$ may 
range from about 0.02 to 0.5 . The time delay $\Delta t$ for the detection of the nucleation peak was in the range between 1 and $10 \mathrm{~s}$. The upper and lower estimates of the nucleation parameters given above yield $J_{\text {crit }}$ between about $5 \cdot 10^{8} \mathrm{~cm}^{-3} \mathrm{~s}^{-1}$ and $10^{13} \mathrm{~cm}^{-3} \mathrm{~s}^{-1}$. According to the activity-based parameterisation of $J$ by Koop et al. (2000), this corresponds to $\Delta a_{w}$ of 0.30 and 0.32 , respectively, where $\Delta a_{w}$ denotes the difference between the water activities of the ice nucleating particles and particles in equilibrium with ice. Assuming equilibrium conditions, the corresponding temperature dependent ice saturation ratio $S_{\text {ice }}(T)$ is given by

$S_{\text {ice }}(T)=1+\Delta a_{w} \frac{p_{w, 0}(T)}{p_{\mathrm{w}, \text { ice }}(T)}$

where $p_{w, 0}$ and $p_{\mathrm{w} \text {,ice }}$ are the liquid water and ice saturation pressures. Figure 7 shows that most of the experimental data are consistent with this parameterisation, except for a few outliers above $218 \mathrm{~K}$ which have been discussed above, and a systematic tendency to higher $S_{\text {nuc }}$ at the lowest temperature where diffusion limitation to large particles becomes important, as discussed in more detail in the companion paper (Haag et al., 2003).

\section{Conclusions}

It has been shown that well-defined supersaturations with respect to the ice phase, characteristic of orographic waves in the upper troposphere and lower stratosphere, can be established in sulphuric acid aerosols using the method of expansion cooling in a large cryogenic aerosol chamber with icecoated walls. Saturation ratios were derived from gas temperatures and total water concentration measured with a fast Lyman- $\alpha$ hygrometer (FISH) and corrected for the amount of water taken up by the sulphuric acid aerosols. The methodology was used to determine critical supersaturations $S_{\text {nuc }}$ between 231 and $189 \mathrm{~K}$ for homogeneous ice nucleation in supercooled sulphuric acid aerosols with particles in the size range between about 0.05 and $1 \mu \mathrm{m}$. This range is characteristic of the Junge aerosol in the lower stratosphere. Cooling rates at the time of ice nucleation varied between approximately zero and $-2.8 \mathrm{~K} \mathrm{~min}^{-1}$.

A recent parameterisation of the ice nucleation rate $J$ in solution droplets, based on experiments under different laboratory conditions, yields $S_{\text {nuc }}$ as function of the difference between the activity of water in the supercooled droplets and in a solution in equilibrium with ice at the same temperature (Koop et al., 2000). The results of 24 measurements in the large aerosol chamber were used to test the validity of this parameterisation under close-to-atmospheric conditions. Most of the results agree with the parameterisation within their error limits. A tendency of the experimental results to exceed the predicted $S_{\text {nuc }}$ at lower temperatures is attributed to non-equilibrium effects, i.e. diffusion-limited uptake of water vapour by the larger particles during the cooling process. This and other dynamic effects are studied quantitatively with a microphysical model in a companion paper (Haag et al., 2003).

Acknowledgements. Running the AIDA facility for freezing experiments was only possible with continuous support by all staff members, especially R. Buschbacher, E. Kranz, and G. Scheurig. We would also like to thank S. L. Clegg for giving access to the AIM model. Helpful discussions with B. P. Luo, T. Koop, P. J. DeMott, and D.C. Rogers are also acknowledged. This work contributes to the HGF (Hermann-von-Helmholtz-Gemeinschaft Deutscher Forschungszentren) project "Particles and Cirrus Clouds" (PAZI) and has been funded by BMBF (AFO2000 project POSTA, 07ATF04) and by the European Commission (FP5 project CIPA, EVK2-CT2000-00095). We also thank two anonymous reviewers for constructive interactive discussion of this work.

\section{References}

Bertram, A. K., Patterson, D. D., and Sloan, J. J.: Mechanisms and Temperatures for the freezing of sulfuric acid aerosols measured by FTIR extinction spectroscopy, J. Phys. Chem., 100, 23762383, 1996.

Bunz, H., Koyro, M., and Scheurig, G.: Numerical simulation of the conditioning of volatile particles in laminar flow tube reactors, Aerosol Sci. Technol., 36, 934-940, 2002.

Carslaw, K. S., Clegg, S. L., and Brimblecombe, P.: A thermodynamic model of the system $\mathrm{HCl}-\mathrm{HNO}_{3}-\mathrm{H}_{2} \mathrm{SO}_{4}-\mathrm{H}_{2} \mathrm{O}$, including solubilities of $\mathrm{HBr}$, from $<200 \mathrm{~K}$ to $328 \mathrm{~K}$, J. Phys. Chem., 99, 11 557-11 574, 1995.

Carslaw, K.S., Peter, T., and Clegg, S. L.: Modeling the composition of liquid stratospheric aerosols, Rev. Geophys., 35, 125-154, 1997.

Carslaw, K.S., Wirth, M., Tsias, A., Luo, B.P., Dörnbrack, A., Leutbecher, M., Volkert, H., Renger, W., Bacmeister, J. T., and Peter, T.: Particle microphysics and chemistry in remotely observed mountain polar stratospheric clouds, J. Geophys. Res.Atmos., 103 (D5), 5785-5796, 1998 a.

Carslaw, K.S., Wirth, M., Tsias, A., Luo, B.P., Dörnbrack, A., Leutbecher, M., Volkert, H., Renger, W., Bacmeister, J. T., Reimer, E., and Peter, T.: Increased stratospheric ozone depletion due to mountain-induced atmospheric waves, Nature, 391, 675-678, 1998b.

Chen, Y.L., DeMott, P.J., Kreidenweis, S.M., Rogers, D.C., and Sherman, D.E.: Ice formation by sulfate and sulfuric acid aerosol particles under upper-tropospheric conditions, J. Atmos. Sci., 57, 3752-3766, 2000.

Clegg, S. L., Brimbleconbe, P., and Wexler, A. S.: Thermodynamic model of the system $\mathrm{H}^{+}-\mathrm{NH}_{4}^{+}-\mathrm{SO}_{4}^{2-}-\mathrm{NO}_{3}^{-}-\mathrm{H}_{2} \mathrm{O}$ at tropospheric temperatures, J. Phys. Chem., 102, 2137-2154, 1998.

Davies, C. N.: The entry of aerosols into sampling tubes and heads, Brit. J. Appl. Phys. (J. Phys. D), 1, 921-932, 1968.

Demott, P. J. and Rogers, D. C.: Freezing nucleation rates of dilute solution droplets measured between $-30^{\circ}$ and $-40^{\circ} \mathrm{C}$ in laboratory simulations of natural clouds, J. Atmos. Sci., 47, 10561064, 1990.

Field, P. R., Cotton, R. J., Noone, K., Glantz, P., Kaye, P. H., Hirst, E., Greenaway, R. S., Jost, C., Gabriel, R., Reiner, T., Andreae, M., Saunders, C.P.R., Archer, A., Choularton, T., Smith, M., 
Brooks, B., Hoell, C., Bandy, B., Johnson, D., and Heymsfield, A.: Ice nucleation in orographic wave clouds: Measurements made during INTACC, Q. J. Roy. Meteor. Soc., 127, 1493-1512, 2001.

Gierens, K., Schumann, U., Helten, M., Smit, H., and Wang, P. H.: Ice-supersaturated regions and subvisible cirrus in the northern midlatitude upper troposphere, J. Geophys. Res.-Atmos., 105 (D18), 22 743-22 753, 2000.

Haag, W., Kärcher, B., Schaefers, S., Stetzer, O., Möhler, O., Schurath, U., Krämer, M., and Schiller, C.: Numerical simulations of homogeneous freezing processes in the aerosol chamber AIDA, Atmos. Chem. Phys., 3, 195-210, 2003.

Heymsfield, A. J. and Miloshevich, L. M.: Homogeneous Ice Nucleation and Supercooled Liquid Water in Orographic Wave Clouds, J. Atmos. Sci., 50, 2335-2353, 1993.

Jensen, E. J. and Toon, O. B.: Ice Nucleation in the Upper Troposphere - Sensitivity to Aerosol Number Density, Temperature, and Cooling Rate, Geophys. Res. Lett., 21, 2019-2022, 1994.

Jensen, E. J., Toon, O. B., and Hamill, P.: Homogeneous Freezing Nucleation of Stratospheric Solution Droplets, Geophys. Res. Lett., 18, 1857-1860, 1991.

Jensen, E. J., Kinne, S., and Toon, O. B.: Tropical Cirrus Cloud Radiative Forcing - Sensitivity Studies, Geophys. Res. Lett., 21, 2023-2026, 1994.

Jensen, E. J., Toon, O. B., Tabazadeh, A., Sachse, G. W., Anderson, B. E., Chan, K. R., Twohy, C. W., Gandrud, B., Aulenbach, S. M., Heymsfield, A., Hallett, J., and Gary, B.: Ice nucleation processes in upper tropospheric wave-clouds observed during SUCCESS, Geophys. Res. Lett., 25, 1363-1366, 1998.

Jensen, E. J., Read, W. G., Mergenthaler, J., Sandor, B. J., Pfister, L., and Tabazadeh, A.: High humidities and subvisible cirrus near the tropical tropopause, Geophys. Res. Lett., 26, 2347-2350, 1999.

Jensen, E.J., Toon, O. B., Vay, S. A., Ovarlez, J., May, R., Bui, T. P., Twohy, C. H., Gandrud, B. W., Pueschel, R. F., and Schumann, U.: Prevalence of ice-supersaturated regions in the upper troposphere: Implications for optically thin ice cloud formation, J. Geophys. Res.-Atmos., 106 (D15), 17 253-17 266, 2001.

Kärcher, B.: Properties of subvisible cirrus clouds formed by homogeneous freezing, Atmos. Chem. Phys., 2, 161-170, 2002.

Kärcher, B. and Lohmann, U.: A parameterization of cirrus cloud formation: Homogeneous freezing of supercooled aerosols, J. Geophys. Res., 107 (D2), 101029/2001JD000470, 2002.

Knopf, D., Zink, P., Schreiner, J., and Mauersberger, K.: Calibration of an aerosol composition mass spectrometer with sulfuric acid water aerosol, Aerosol Sci. Technol., 35, 924-928, 2001.

Koop, T., Ng, H. P., Molina, L. T., and Molina, M. J.: A new optical technique to study aerosol phase transitions: The nucleation of ice from $\mathrm{H}_{2} \mathrm{SO}_{4}$ aerosols, J. Phys. Chem. A, 102, 8924-8931, 1998.

Koop, T., Luo, B.P., Tsias, A., and Peter, T.: Water activity as the determinant for homogeneous ice nucleation in aqueous solutions, Nature, 406, 611-614, 2000.

Lawson, R. P., Heymsfield, A.J., Aulenbach, S.M., and Jensen, T. L.: Shapes, sizes and light scattering properties of ice crystals in cirrus and a persistent contrail during SUCCESS, Geophys. Res. Lett., 25, 1331-1334, 1998.

Lohmann, U. and Kärcher, B.: First interactive simulations of cirrus clouds formed by homogeneous freezing in the ECHAM general circulation model, J. Geophys. Res., 107 (D10), 10.1029/2001JD000767, 2002.

Marti, J. and Mauersberger, K.: A survey and new measurements of ice vapor pressure at temperatures between 170 and $250 \mathrm{~K}$, Geophys. Res. Lett., 20, 363-366, 1993.

Martin, S. T.: Phase transitions of aqueous atmospheric particles, Chem. Rev., 100, 3403-3453, 2000.

Möhler, O., Nink, A., Saathoff, H., Schaefers, S., Schnaiter, M., Schöck, W., and Schurath, U.: The Karlsruhe aerosol chamber facility AIDA: technical discription and first results of homogeneous and heterogeneous ice nucleation experiments, Proc. of Workshop on Ion-Aerosol-Cloud-Interactions (IACI), (Ed) Kirkby, J., CERN 2001-007, Geneva, 2001.

Nink, A., Saathoff, H., Schnaiter, M., and Möhler, O.: Laboratory investigation of the impact of aircraft particulate emissions on cirrus cloud formation, Proc. of European workshop on aviation, aerosols, contrails, and cirrus clouds (A2C3), (Eds) Schumann, U. and Amanatidis, G. T., EUR19428, 149-153, Seeheim, 2000.

Peter, T.: Microphysics and heterogeneous chemistry of polar stratospheric clouds, Annu. Rev. Phys. Chem., 48, 785-822, 1997.

Prenni, A. J., Wise, M.E., Brooks, S.D., and Tolbert, M. A.: Ice nucleation in sulfuric acid and ammonium sulfate particles, J. Geophys. Res., 106 (D3), 3037-3044, 2001.

Solomon, S.: Stratospheric ozone depletion: A review of concepts and history, Rev. Geophys., 37, 275-316, 1999.

Tabazadeh, A., Jensen, E. J., and Toon, O. B.: A model description for cirrus cloud nucleation from homogeneous freezing of sulfate aerosols, J. Geophys. Res.-Atmos., 102 (D20), 23 845-23 850, 1997a.

Tabazadeh, A., Jensen, E. J., and Toon, O. B.: Formation and implications of ice particle nucleation in the stratosphere, Geophys. Res. Lett., 24, 2007-2010, 1997.

Schreiner, J., Voigt, C., Kohlmann, A., Amold, F., Mauersberger, K., and Larsen, N.: Chemical analysis of polar stratospheric cloud particles, Science, 283, 968-970, 1999.

Schreiner, J., Voigt, C., Zink, P., Kohlmann, A., Knopf, D., Weisser, C., Budz, P., and Mauersberger, K.: A mass spectrometer system for analysis of polar stratospheric aerosols, Rev. Sci. Instr., 73, 446-452, 2002.

Voigt, C., Schreiner, J., Kohlmann, A., Zink, P., Mauersberger, K., Larsen, N., Deshler, T., Kroger, C., Rosen, J., Adriani, A., Cairo, F., Di Donfrancesco, G., Viterbini, M., Ovarlez, J., Ovarlez, H., David, C., and Dörnbrack, A.: Nitric acid trihydrate (NAT) in polar stratospheric clouds, Science, 290, 1756-1758, 2000.

Zink, P., Knopf, D. A., Schreiner, J., Mauersberger, K., Möhler, O., Saathoff, H., Seifert, M., Tiede, R., and Schurath, U.: Cryo-chamber simulation of stratospheric $\mathrm{H}_{2} \mathrm{SO}_{4} / \mathrm{H}_{2} \mathrm{O}$ particles: composition analysis and model comparison, Geophys. Res. Lett., 29, 10.1029/2001GL013296, 2002.

Zöger, M., Afchine, A., Eicke, N., Gerhards, M.-T., Klein, E., McKenna, D.S., Mörschel, U., Schmidt, U., Tan, V., Tuitjer, F., Woyke, T., and Schiller, C.: Fast in situ stratospheric hygrometers: A new family of balloon-borne and airborne Lyman a photofragment fluorescence hygrometers, J. Geophys. Res., 104 (D1), 1807-1816, 1999. 